\title{
Bad company
}

The presence or absence of different types of immune cells is known to influence the outcome for patients with cancer, but we are still some way from understanding the complex interactions between immune cell subsets and how these cells affect tumour growth and regression. A paper published in Cancer Discovery shows that the response of patients with breast cancer to specific chemotherapies is influenced by the subsets of leukocytes that are present in the tumour.

Previous studies have shown that tumour-associated macrophages (TAMs) correlate with a poor prognosis in several tumour types, that TAMs are recruited to tumours by colony-stimulating factor 1 (CSF1) and interleukin-34 (IL-34), and that, in the absence of $\mathrm{CD}^{+} \mathrm{T}$ cells, $\mathrm{CD} 4^{+}$ $\mathrm{T}$ cells increase the pro-tumour activity of CD68 ${ }^{+}$TAMs. Building on these data, Lisa Coussens and colleagues examined the numbers of $\mathrm{CD}^{+}, \mathrm{CD}^{+}$and $\mathrm{CD} 68^{+}$leukocytes in breast cancer tissue. High $\mathrm{CD}^{+}$ $\mathrm{T}$ cell and low $\mathrm{CD} 8^{+} \mathrm{T}$ cell numbers correlated with reduced overall survival in chemotherapy-naive breast cancer patients, and the number of $\mathrm{CD}^{+} \mathrm{T}$ cells was inversely correlated with the number of $\mathrm{CD} 68^{+}$TAMs. Furthermore, a CD68 ${ }^{\text {hi }}, \mathrm{CD} 4^{\text {hi }}$ and $\mathrm{CD} 8^{\text {low }}$ immune signature in the tumours was an independent predictor of reduced overall and relapsefree survival in these patients, as well as of reduced relapse-free survival in patients with lymph node metastases at diagnosis.

Coussens and colleagues also found that chemotherapy treatment of human breast cancers increased the numbers of TAMs in the tumour, but had no effect on the presence of $\mathrm{CD} 8^{+} \mathrm{T}$ cells. Moreover, using various mouse models of breast cancer, they established that expression of CSF1 and IL-34 by mouse mammary epithelial cells was induced by chemotherapy and resulted in macrophage recruitment. Inhibition of CSF1 activity in vivo using a CSF1-specific antibody or the tyrosine kinase inhibitor PLX3397 (which targets the CSF1 receptor and KIT) reduced

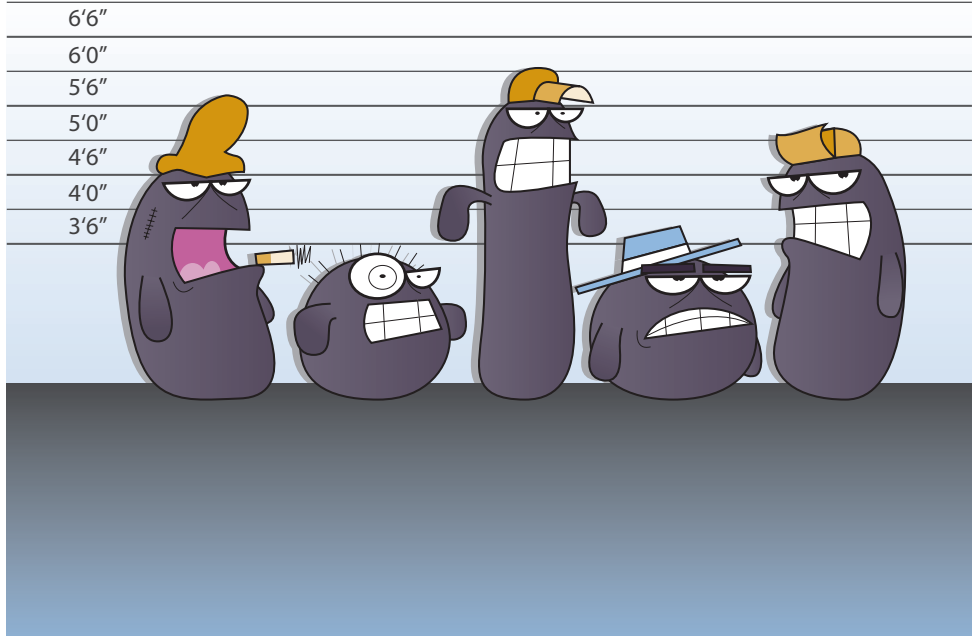

TAM numbers. Importantly, mice with mammary tumours that were treated with the chemotherapeutic agent paclitaxel combined with either CSF1-specific antibody or PLX3397 showed improved survival rates compared with mice treated with each drug as a monotherapy.

The reduction in TAM numbers within the primary tumours increased the numbers of activated $\mathrm{CD}^{+} \mathrm{T}$ cells, and in vitro data indicated that TAMs repress $\mathrm{CD}^{+}$ $\mathrm{T}$ cell proliferation. In addition, deletion of $\mathrm{CD}^{+} \mathrm{T}$ cells from mouse mammary tumours prevented the chemosensitizing effect of PLX3397 combined with paclitaxel, indicating that the effect of this drug combination partly stems from enabling the activation of $\mathrm{CD} 8^{+} \mathrm{T}$ cells by reducing TAM numbers.

Examination of fine-needle aspiration biopsies from patients with newly diagnosed breast cancer prior to neoadjuvant chemotherapy treatment showed that patients with a high ratio of $C D 68$ to $C D 8$ mRNA expression had a significantly lower response to treatment than patients with low CD68 and high CD8 mRNA expression. Taken together, these findings indicate that drugs that prevent macrophage recruitment should be investigated further and that the ability to use immune profiles to identify women who are likely to benefit from such treatment is imperative.

Nicola McCarthy

Chief Editor, Nature Reviews Cancer

ORIGINAL RESEARCH PAPER DeNardo, D. G.

et al. Leukocyte complexity predicts breast cancer survival and functionally regulates response to chemotherapy. Cancer Discovery 3 Apr 2011 (doi:10.1158/2159-8274.CD-10-0028)

This article is modified from the original in Nature Rev. Cancer (doi:10.1038/nrc3056). 